\title{
كزارش مورد
}

\section{كزارش يك مورد تزريق خون نامتجانس در اتاق عمل}

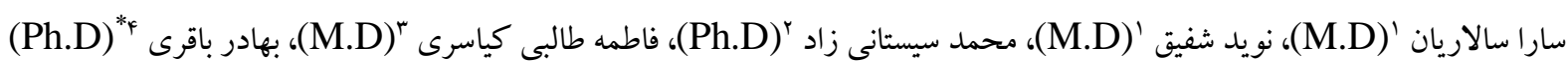

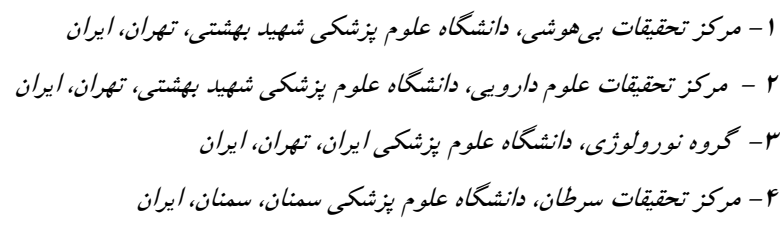

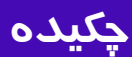

هدف: تزريق خون نامتجانس از نظر سيستم ABO داراى عوارض متعددى است كه خطرناكترين آنها مى تواند واكنش

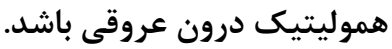

كزارش مورد: بيمار مورد نظر آقاى

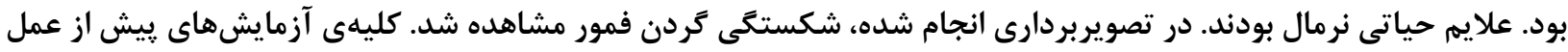

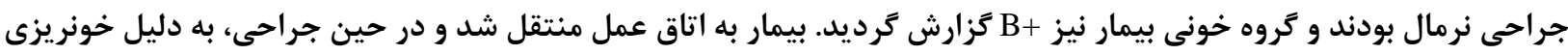

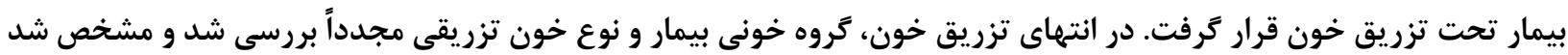

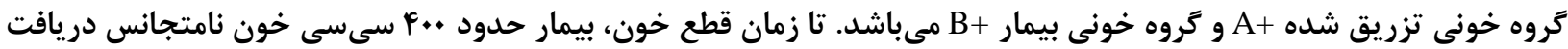

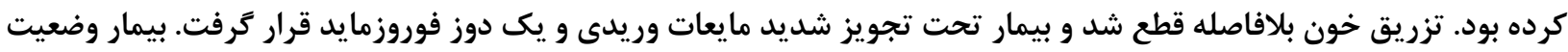

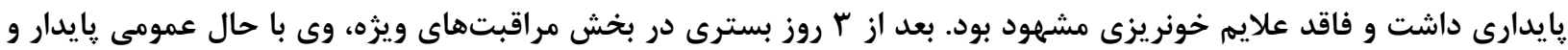

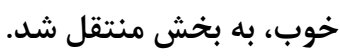

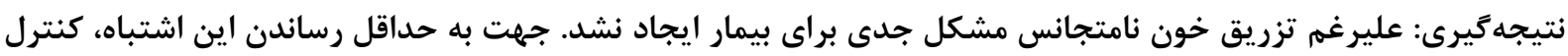

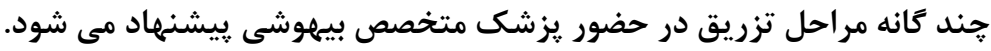

وازههاى كليدى: تزريق خون، تروه خونى، تزارش مورد

بدو ورود از درد زانوى راست شاكى بود. علايم حياتى نرمال

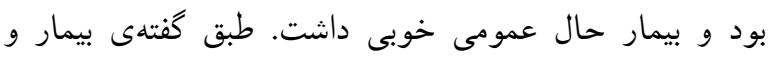

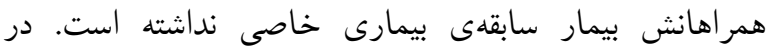

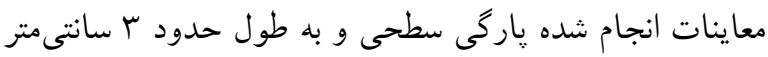
بر زانوى راست و محدوديت حركتى در ران سمت راست دئ ديده

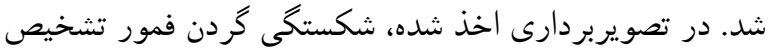

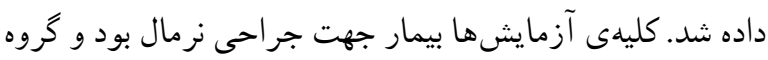
خونى بيمار B+ كزارش خرديد.

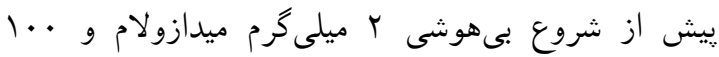

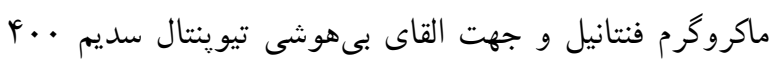

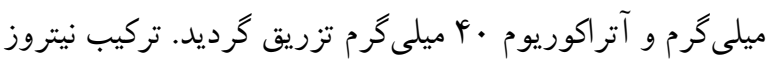
اكسايد و ايزوفلوران جهت ادامهى بىهوشى استفاده شد.

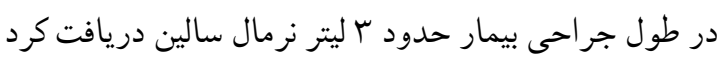

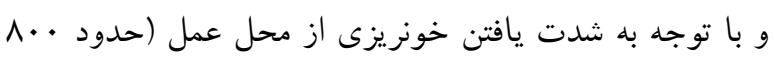

\section{مقدمه}

تزريق خون نامتجانس از نظر سيستم ABO داراى عوارض

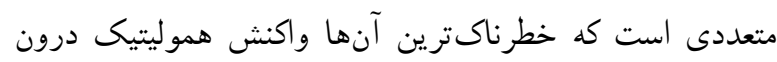

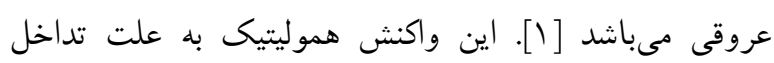
آنتىبادىهاى عليه آنتىزنهاى

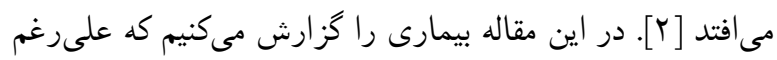

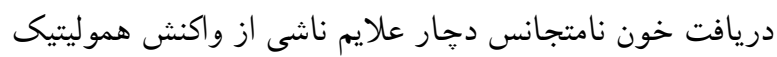

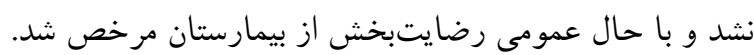

\section{كزارش مورد}

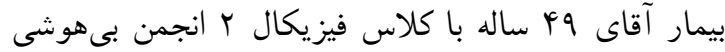

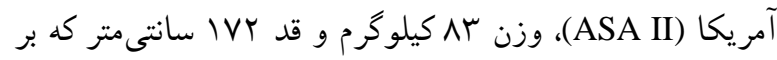

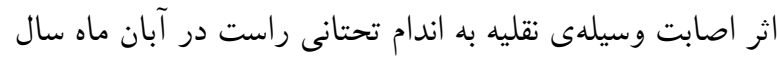

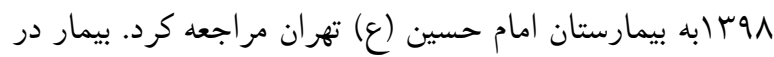




\begin{tabular}{|c|c|c|}
\hline بعد از تزريق خون & قبل از تزريق خون & 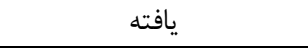 \\
\hline$r q / 1$ & rघ/A & دما (C) \\
\hline$V \Delta$ & VT & ضربان قلب (beats/min) \\
\hline ITN/AD & $1 \pi 9 / \wedge \Delta$ & فشار خون (mmHg) \\
\hline 19 & IV & تعداد تنفس (breaths/min) \\
\hline V/ra & $V / \mu \Lambda$ & $\mathrm{PH}$ \\
\hline 9. & pF & $\mathrm{PCO} 2(\mathrm{mmHg})$ \\
\hline זr & rq & $\mathrm{HCO} 3(\mathrm{mEq} / \mathrm{L})$ \\
\hline $111 .$. & $1 f \ldots$ & $\mathrm{WBC} / \mathrm{mcI})$ \\
\hline $1 \cdot / V$ & $1 \mathrm{~F} / \mathrm{\Lambda}$ & $\mathrm{Hb}(\mathrm{g} / \mathrm{dL})$ \\
\hline$|\mu| \ldots$ & $190 \ldots$ & Platelet (/mcL) \\
\hline \multicolumn{2}{|c|}{$\Lambda / f$} & \\
\hline \multicolumn{2}{|c|}{ TIA } & $\begin{array}{r}\text { FDP }(\mathrm{mcg} / \mathrm{mL}) \\
\text { Fibringon }(\mathrm{mo} / \mathrm{dL})\end{array}$ \\
\hline \multicolumn{2}{|c|}{ rq } & $\mathrm{D}$ dimer $(\mathrm{ng} / \mathrm{mL})$ \\
\hline \multicolumn{2}{|c|}{$\mathrm{B}+$} & Blood Group \\
\hline \multicolumn{2}{|c|}{1} & Reticulocyte Count (\%) \\
\hline \multicolumn{2}{|c|}{$\cdot / \& \Delta$} & \\
\hline \multicolumn{2}{|c|}{ ir } & BUN (mo/dL) \\
\hline \multicolumn{2}{|c|}{$\cdot / \Lambda$} & $\mathrm{Cr}(\mathrm{mg} / \mathrm{dL})$ \\
\hline
\end{tabular}

\section{بحث و نتيجه كيرى}

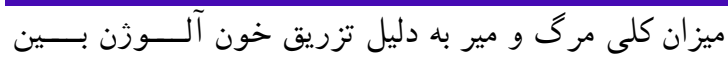

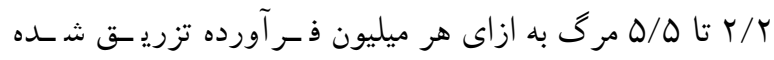

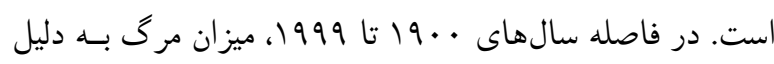

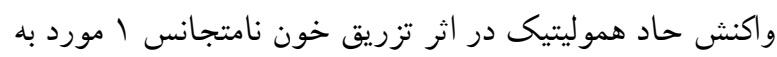

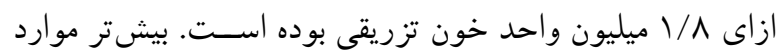

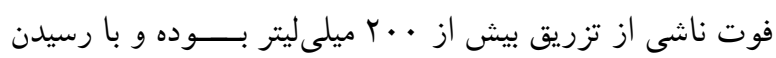

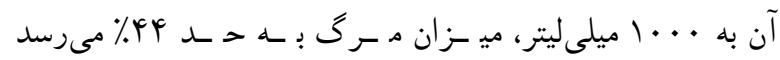

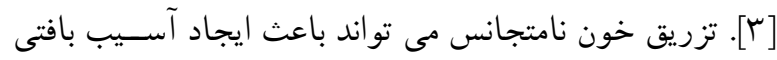

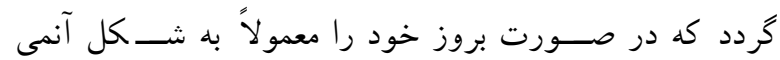

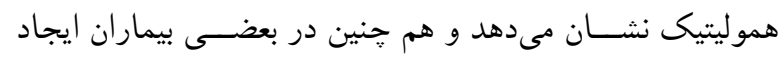

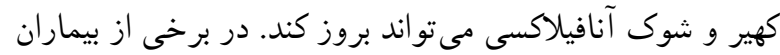

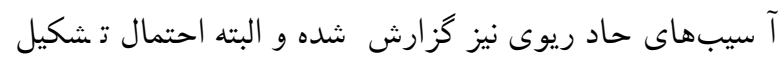

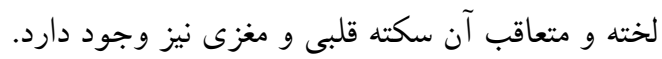

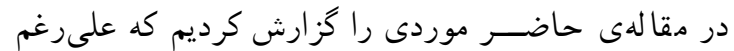

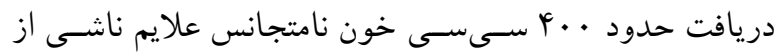

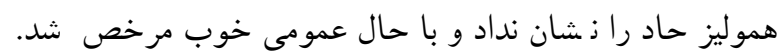

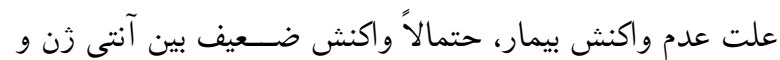

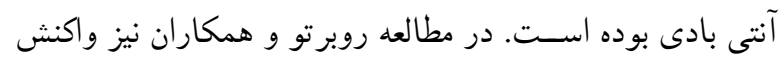

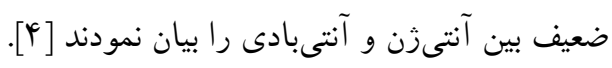

طالقانى و همكاران در سال بو موردى را گزارش كردند كه

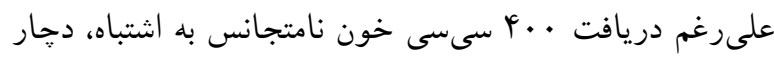

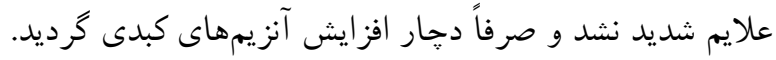

سىسى خونريزى) به همراه افت فشار خون دستور به تزريق

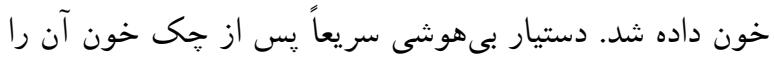

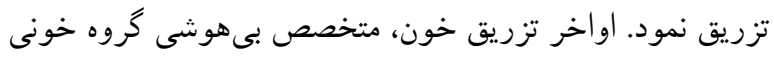

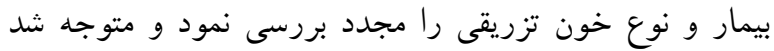

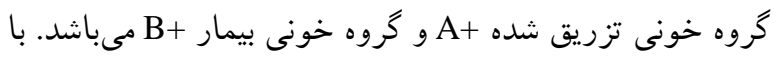

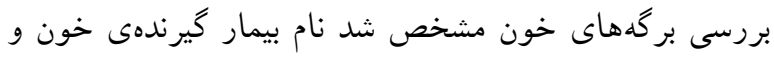

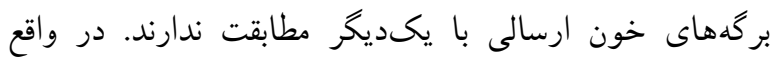

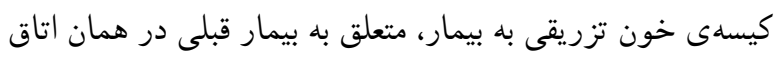

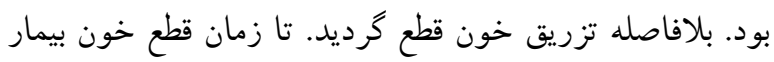

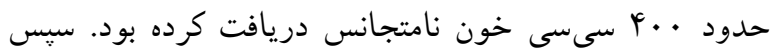

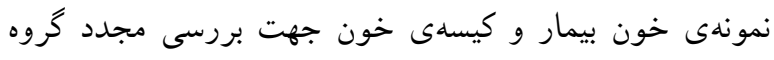

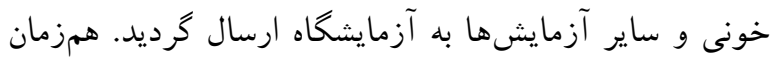

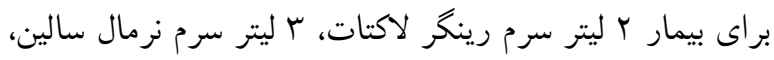

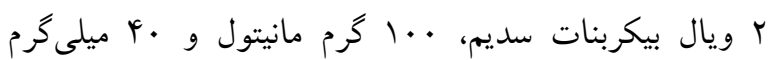

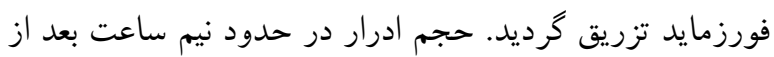

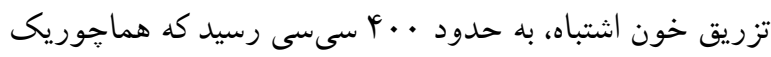

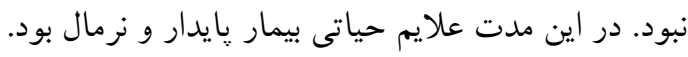

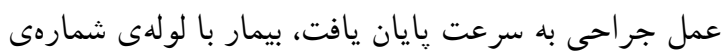

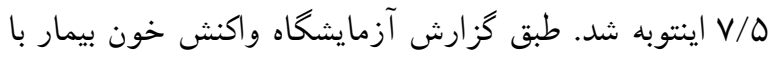

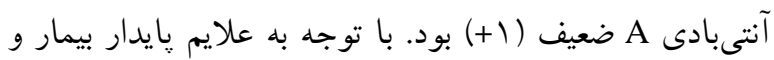

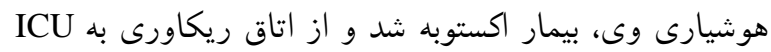

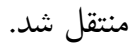
در بخش مراقبتهاى ويزه بيمار كاملاً هوشيار بود و علايم حياتى وى تغييرى نداشتند. بيمار در ICU تحت نظر قرار كرفت و حجم مايعات بيمار طورى تنظيم شد كه حجم ادرار وى 1

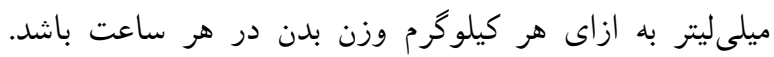

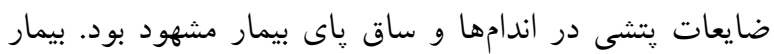

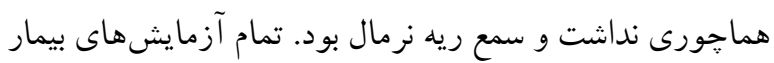
نيز نرمال بود (جدول () ). در ساعات اوليهى ورود بيمار به بخش مراقبتهاى ودئ ويزه

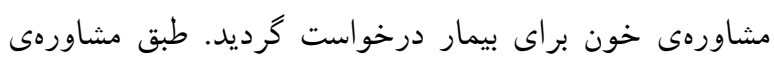

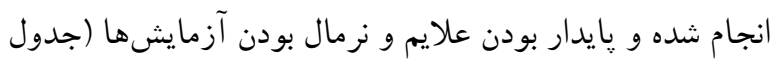

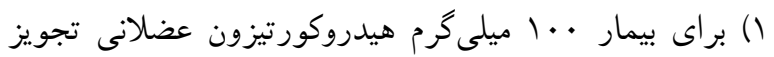

بيمار مورد نظر ب روز در بخش مراقبتهاى ويزه تحت نظر

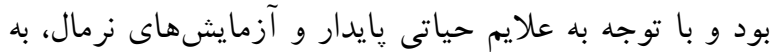
بخش جر احى منتقل شد. جدول 1. يافته هاى كلينيكى و ياراكلينيكى بيمار 


\section{تشكر و قدردانى}

نويسندكان اين مقاله از يرسنل محترم اتاق هاى عمل بيمارستان امام حسين (ع) تهران، تقدير و سباسگز ارى مى مينمايند.

\section{منابع}

[1] Webster BH. Clinical presentation of haemolytic transfusion reactions. Anaesth Intensive Care 1980; 8: 115-119.

[2] Weinstock C, Möhle R, Dorn C, Weisel K, Höchsmann B, Schrezenmeier H, Kanz L. Successful use of eculizumab for treatment of an acute hemolytic reaction after $\mathrm{ABO}$-incompatible red blood cell transfusion. Transfusion 2015; 55: 605-610.

[3] Vamvakas EC, Blajchman MA. Transfusion-related mortality: the ongoing risks of allogeneic blood transfusion and the available strategies for their prevention. Blood 2009; 113: 34063417.

[4] Reverberi R, Reverberi L. Factors affecting the antigenantibody reaction. Blood Transfus 2007; 5: 227.

[5] Ghasemi M, Malek B, Tavakolpour A, Vosoughian M, Dahi Taleghani M. Mismatched blood transfusion; case-report. Scientific J Iran Blood Transfus Organ 2013; 10. (Persian).

[6] Dahi M, Dabagh A. Transfusion of unmatched packed cells in a life threatening emergency case. Scientific J Iran Blood Transfus Organ 2006; 3. (Persian).

[7] Ti LK, Ang SBL, Chen FG. Survival after large ABOincompatible blood transfusion. Can J Anesth 1998; 45: 916
بيمار پِ از سه روز با نرمال شدن آنز يمهاى كبدى از بيمارستان

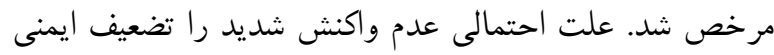
ناشى از لوسمى ذكر كردند [0]

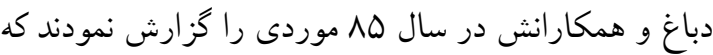

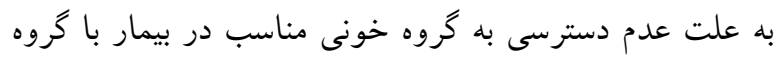

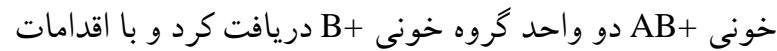
حمايتى و بدون بروز واكنشهاى شديد از بيمارستان مرخص شدر شردان

در سال 1991 نيز موردى گزارش گرديد كه كودى ه, با.

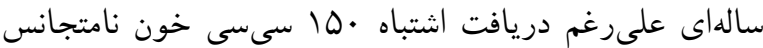

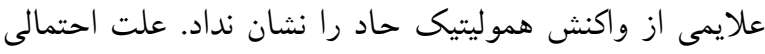

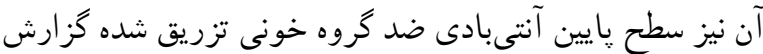

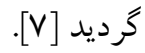

در مطالعهى حاضر به نظر مىرسد بيمار مورد نظر از سطح

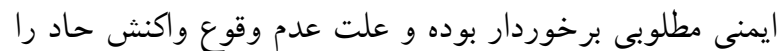

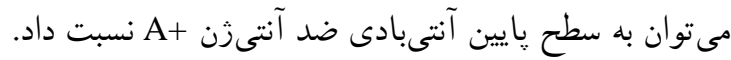

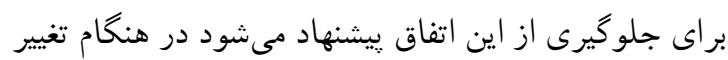
شيفت برسنل تحويل كيسه خون انجام نشود، در هنخام تحويل كيسه خون توسط برسنل جكى مجدد قبل از تزريق انجام شود و و در هنگام تزريق حتماً متخصص بى هوشى حضور داشته باشد. 


\section{Case Report \\ A case report of heterogeneous blood transfusion in the operating room}

Sara Salarian (M.D) ${ }^{1}$, Navid Shafigh (M.D) ${ }^{1}$, Mohammad Sistanizad (Ph.D) ${ }^{2}$, Fatemeh Talebi kiasari (M.D) ${ }^{3}$, Bahador Bagheri (Ph.D) ${ }^{* 4}$

1 - Anesthesiology Research Center, Shahid Beheshti University of Medical Sciences, Tehran, Iran

2 - Pharmaceutical Sciences Research Center, Shahid Beheshti University of Medical Sciences, Tehran, Iran

3- Department of Neurology, Iran University of Medical Sciences, Tehran, Iran

4- Cancer Research Center, Semnan University of Medical Sciences, Semnan, Iran

* Corresponding author. +989123268059 Bahadordvm@ yahoo.com

Received: 27 Dec 2019; Accepted: 22 Jun 2020

Introduction: Mismatched-blood transfusions in the ABO-system may lead to severe of complications such as intravascular hemolysis.

Case report: A 49-year-old man suffering from a right lower limb injury due to accident was admitted to hospital. Vital signs were normal. X-ray showed a femoral neck fracture. Before surgery, all of lab tests were in normal values and B+ blood- group was reported. During surgery and due to blood loss, the patient underwent blood transfusion. At the end of transfusion, a mismatched blood bag was observed. The patient had received about $400 \mathrm{cc}$ mismatchedblood. Transfusion was promptly terminated and the patient received extensive IV fluids in addition to a single dose of furosemide. The patient had stable status without signs of overt hemolysis. After 3 days stay at intensive care unit, he was transferred to the ward with a stable status.

Conclusion: In spite of mismatched blood transfusion, the patient did not experience severe adverse events. To prevent this problem, different steps of blood transfusion should be checked by anesthesiologist.

Keywords: Blood Transfusion, Blood Group, Case Reports. 